\title{
BMJ Open Diabetes Research \& Care
}

To cite: John J-R, Groves T. BMJ Open Diabetes Research \& Care. BMJ Open Diabetes Research \& Care 2013;1: e000001. doi:10.1136/ bmjdrc-2013-000001

This final article is available for use under the terms of the Creative Commons Attribution Non-Commercial 3.0 Licence; see http://bmjdrc.bmj.com

${ }^{1}$ North American Publisher and Journal Business Director, BMJ

${ }^{2}$ Editor-in-Chief, BMJ Open

Correspondence to Joyce-Rachel John; jrjohn@ bmj.com

Joyce-Rachel John, ${ }^{1}$ Trish Groves ${ }^{2}$

We are pleased to announce the launch of BMJ Open Diabetes Research E Care - a new online-only, open access research journal published by BMJ in partnership with the American Diabetes Association.

As a pioneer in the open access movement, $\mathrm{BMJ}$ understands the need to communicate medical advances to the widest possible audience, and is proud to usher this important new journal into the literature. An estimated 26 million Americans live with type 2 diabetes, many with associated complications such as cardiovascular disease and obesity. The increasing worldwide burden of diabetes has prompted a rapid burgeoning of diabetes research and the launch and approval of new drug classes to manage type 2 diabetes. BMJ's mission is to advance healthcare by sharing knowledge, and we believe that new epidemiology and evaluations of new treatment approaches are best disseminated internationally and rapidly.

BMJ will ensure that BMJ Open Diabetes Research E् Care satisfies the open access mandates of governments, institutions and funding bodies, such as the National Institutes of Health and Wellcome Trust. Authors will retain copyright and publish under a Creative Commons license, and the full text of papers will be fully accessible online at BMJ Open Diabetes Research $\mathcal{E}$ Care and through PubMed Central.

BMJ Open Diabetes Research E Care will be a high-quality, indexed journal that will only accept original research and rapidly publish articles after peer review. The journal will consider research that covers all aspects of type 1 and type 2 diabetes mellitus, including basic science and clinical research.

We are delighted and honoured to partner with the American Diabetes Association on this journal. The association is a leader in the fight to stop diabetes and in funding research. The strength of our partnership will ensure that the published research is respected, valued and will positively influence healthcare outcomes. BMJ looks forward to working with the diabetes research community to develop a stronger understanding of this disease. 